\title{
Artificial Intelligence in Corporate Governance Systems
}

\author{
Rizvan Turluev ${ }^{1}$, and Laura Hadjieva ${ }^{2}$ \\ ${ }^{1}$ Chechen State University, 364024 Grozny, Russia \\ ${ }^{2}$ Grozny State Oil Technical University, 364061 Grozny, Russia
}

\begin{abstract}
The presence of a direct causal relationship between management decisions and the analytical and research role of information allows us to prove the strategic importance of information resources. Typically, the need for data is considered at the management level of a company or organization. This position indicates the unambiguity of the confirmation regarding the results of the analyzed data and the possibility of their monetization. Information data is a kind of fundamental basis, demanded by the key structural links of any company. Information serves as an effective identifier of the company's potential opportunities and probable losses in an unstable business environment, as well as quality support from strategically significant initiatives. Of no small importance today is attached to the possibilities of joint application of relevant information on the part of all divisions of the company in order to react as quickly as possible to the transformation of the economic space. It should be noted that information is a kind of asset, the level of efficiency of which is especially important for successful activity. The article discusses artificial intelligence in corporate governance systems.
\end{abstract}

\section{Introduction}

Artificial intelligence in corporate governance systems is understood as a concept that describes how information is planned and collected, created and organized, used and controlled, disseminated and removed. The process ensures that valuable data / information is identified and used to support the operation of the company and increase the cost of business processes.

\section{Materials and methods}

When writing this article, such methods of scientific research were applied as the study of scientific literature on the topic of work, the regulatory framework, analytical and comparative methods.

\section{Results and discussion}

Artificial intelligence in corporate governance systems can be represented not only by raw data management, but is considered from the point of view of contextual metadata, 
additional "information about information", taking into account "information in context" ("data in context"). Information management is represented by analysis and modeling, management and working with repositories, as well as extraction, transformation and loading. Among other things, in the management process, quality characteristics are ensured and information is protected, encrypted and any work with metadata, including architecture. There are a number of critical factors that will ensure maximum management success. All users are guaranteed access to information through different channels, as well as the value of the exploited data. At the same time, data sharing is not limited only within the company, but is also available to other organizations, and the quality characteristics are mai

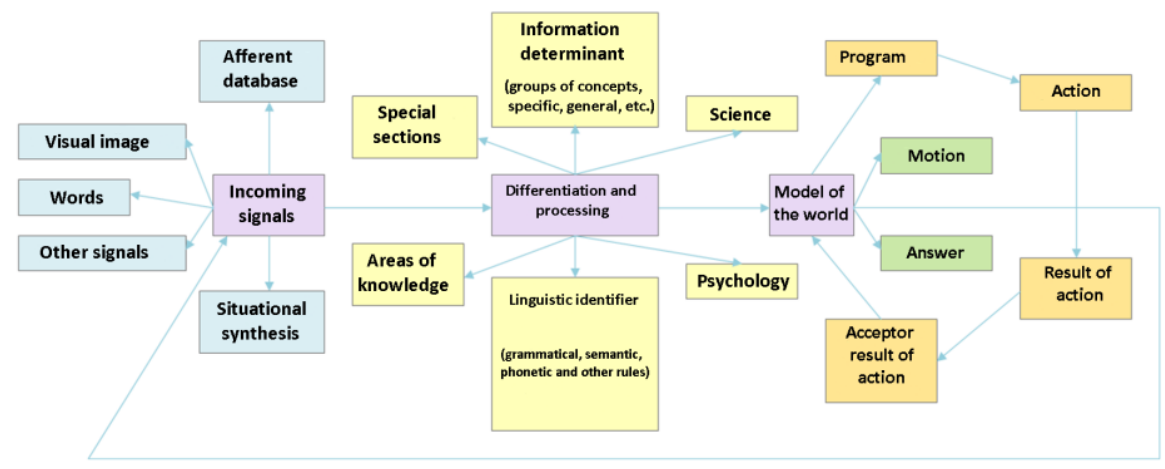

Fig. 1. Artificial intelligence system

Considerable importance is attached to the legal requirements for the security and protection of private information, their integrity and confidentiality, which makes it possible to ensure the highest possible efficiency and effectiveness of the company's information processing activities. The information model defines the key entities and relationships that prevent redundancy as well as architectural degradation. The company may have historical, but already unused data, as well as information that is not available to potential users [6]. The information provided to a wide range of people, insufficiently effective and outdated methods of collecting, storing and analyzing, using data, require special attention. In some cases, the company is unable to cope with obtaining the required information, quality degradation and loss of integrity.

It is also necessary to take into account the fact that there is not always a real opportunity to understand whether the information received really has the initial data of a sufficiently high quality. The complexity of the data evaluation is due to the initial lack of special indicators required for comparative analysis. For example, we will mention low quality data obtained as a result of poor validation during procedures such as entering and / or performing an update, which ultimately do not allow for reliable reporting. Among other things, the consistency of all information that is generated by different operational and internal systems formed and used in the process of activity is of no small importance. 


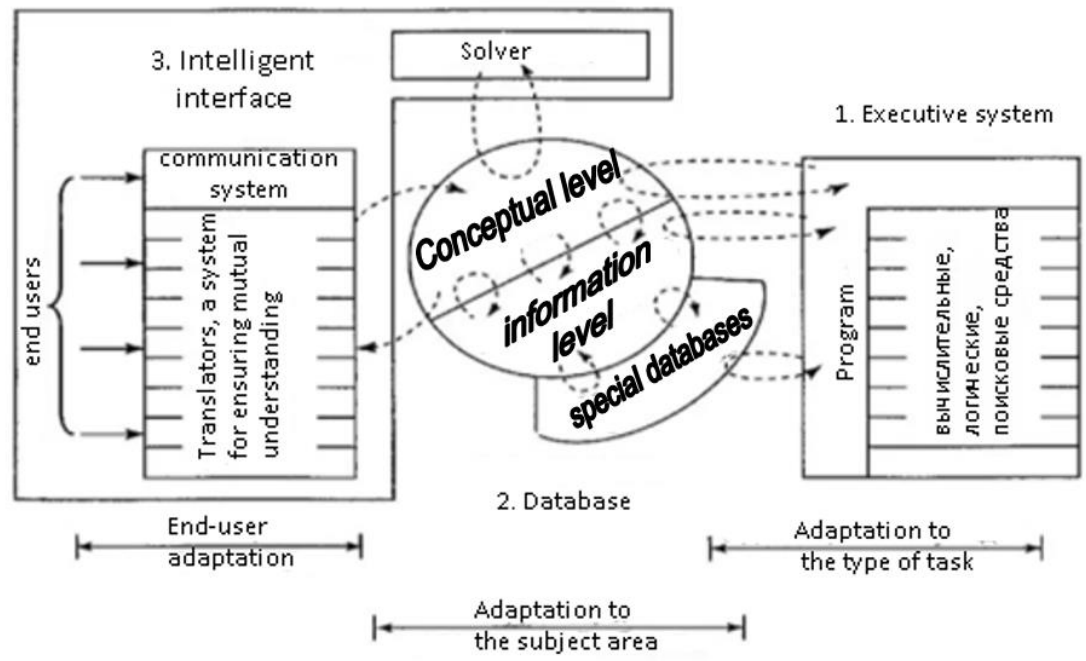

Fig. 2. Functional structure of using an artificial intelligence system

In the broadest sense of the word, today, information management is the use of a large number of modern technologies, various standards and promising processes. However, key issues related to the qualitative characteristics of information (security level, compliance with corporate ethics and the provisions of regulatory enactments focus on the correctness of reference information and consistency, metadata and master data. In some cases, if necessary, it is allowed to include directions of applied data processing in the form of a DBMS However, at present, a very large number of companies and enterprises are in a state of digital transformation, which contributes to a sharp expansion of the range of information, as well as its volume [3], practicing the method of placing corporate information on cloud resources, or leasing In such situations, there is a change in the requirements for data management with revision of the existing information.

In order to understand the concept of the described processes as correctly as possible, it is necessary to indicate that this category does not include change management, a set of procedures for cleaning, receiving, transforming and loading information (ETL). Among other things, this area does not include master data management (MDM), storage and design, and database administration processes. Despite the fact that some blocks of work can be included in the concept of corporate information management, the phenomenon is usually considered as a management methodology, rather than a set of separate activities. Among other things, a similar key task of corporate information management software is represented by ensuring the qualitative characteristics of data. It is for these reasons that the fullest possible disclosure of the topic of the program requires an analysis of literary sources in terms of providing high-quality data [4].

The management staff of the enterprise must apply a complete and consistent view of organizational activities, including individual divisions and processes, carried out in the modern market.

It is in this way that strategically mature and operational, competent decisions are made. The variety of information technologies in the IT sector forms the so-called landscape of a modern enterprise, which implies that modern, actively developing companies have several dozen special accounting systems that supply information for top management. In modern conditions, a company that works with significant amounts of necessary information, various decentralized sources, insufficient relevance and low data structure, inevitably faces the incredible complexity of solving information management problems [5]. 
Outdated, incorrect, fragmented incomplete, scattered data have an extremely negative effect on the processes of investment return, which is especially important for companies with significant investments in IT support of business projects. The problem of qualitative characteristics of information management and indicators of their integration have a tangible effect on the profitability of companies and enterprises [2]. As a rule, such moments of the corporate environment are based on the heterogeneity of the platform, when information is combined in different formats, both generated in the company and coming from outside. This aspect draws attention to multiple independent packages of information with multiple uncoordinated retrieved data, as well as multiple variants of data and reports. It is especially important to study the variety and complexity of the structural qualities of the data used, as well as the procedure for user access to information, which, due to the likely complexity and labor intensity, can create barriers for operators implementing business processes.

Several areas of management are currently known that relate to activities in Data / Information Management. A significant role belongs to Management of data resources as a tool that obligatorily ensures the visibility and appointment of special responsible personsmanagers to all resources, determines the owners of information (ownership) and metadata. The data administration process provides responsibility for choosing the principle of information needs, building a data inventory and modeling data for a specific company. The conditions include the ability to identify duplication and deficiencies in information, provide support for data content data / information content, as well as measure costs and correctly, defining information value as fully as possible. The Management of data / information technology procedures allow you to manage the IT department that supports the company's information systems by referring to processes such as design and database management. Management of information processes include business processes that are brought by IT services to IT for the application of any information. From this point of view, a company for information management needs to consider in detail such activities as fully controlled creation and collection, access and modification, storage and removal, archiving of information [7].

In accordance with the current practice of best practices, the scope of information management processes is represented by the management of unstructured data not present in standard systems (text, image and sound formats). It is these processes that are most efficiently provided today for all the qualitative characteristics of the stages of the information life cycle, including the collection of requirements and direct operation with its completion under the conditions of already established time limits.

\section{Conclusions}

Of course, the key attention in the framework of the work provided is focused on such a concept as the importance of artificial intelligence in corporate governance systems. Considering all of today's specifics, the teams supporting information management processes can of course also provide business data support. In such a situation, such specialists are given the opportunity to answer questions regarding the meaning, possibilities and formats of using information within the company.

It is according to this scheme that all metadata management is carried out, as well as understanding and explaining the typical characteristics of external data required for the ideal execution of the required business processes. From this point of view, it is extremely important to understand that in the process of creating and reorganizing the processes under consideration, it is important to consider the possibility of reusing information in a particular company. Such a task is now quite deservedly belongs to the category of the most 
important plans from the point of view of the most competent and highly effective information management.

\section{References}

1. I.A. Demchenko, N.A. Kolesnikova, Modern technologies of financial management in Russian companies, 125 (2006)

2. V.V. Dick, O.V. Staroverova, A.I. Urintsov, Technological and organizational virtualization of an enterprise in an information society, 35 (2016)

3. A. Yu. Rymanov, Corporate governance, 576 (2015)

4. V.A. Buterin, next generation smart contract and decentralized application platform. Ethereum White Paper (2013)

5. S. Davidson, De Filippi P., Potts J. Disrupting Governance: The New Institutional Economics of Distributed Ledger Technology (2016)

6. P. Filippi, B. Loveluck, The invisible politics of Bitcoin: governance crisis of a decentralized infrastructure (2018). https://policyreview.info

7. J. Palfreyman, Blockchain for government (2015) https://www.ibm.com

8. M. Iansiti, K.R. Lakhani, The truth about blockchain, 118 (2017) 